\title{
Optimization on Serpentine flow channel of PEMFC using RSM
}

\author{
Dr.V.Lakshminarayanan \\ Department of Mechanical Engineering, \\ B.V.Raju Institute of Technology, Narsapur, Telangana-502313, India. \\ e-mail: lux32engineer@yahoo.co.in
}

\begin{abstract}
The performance of the Proton Exchange Membrane fuel cell (PEMFC) depends on operating and design parameters. In this study, the effect of various pressure, temperature, inlet stoichiometric ratio of reactant mass flow rate and various landing to channel width ratio of $(\mathrm{L}: \mathrm{C}) \mathrm{1:1}$, 1:2, 2:1 and 2:2 with serpentine flow channel of $25 \mathrm{~cm}^{2}$ active area of the PEMFC has been considered. The optimum power density of the PEMFC obtained by optimizing these parameters using the Response Surface Methodology (RSM) has been considered. The numerical power densities of serpentine flow channel with $\mathrm{L}: \mathrm{C}-1: 1,1: 2,2: 1$ and $2: 2$ were found to be $0.308,0.321,0.304$ and $0.312 \mathrm{~W} / \mathrm{cm}^{2}$ by the analysis of variance (ANOVA) using Minitab 17 and obtained combinations of parameters were fed into computational fluid dynamics (CFD) Fluent software and the corresponding experimental power density was to be $0.250,0.260,0.259$ and $0.260 \mathrm{~W} / \mathrm{cm}^{2}$ respectively. It was found that the numerical studies on serpentine flow field results has been deviated from the experimental results for various $L: C$ of 1:1, 1:2, 2:1 and 2:2 as $19.2 \%, 16.5 \%, 16.2 \%$ and $11.9 \%$ respectively.
\end{abstract}

Keyword - Response Surface Methodology, computational fluid dynamics, serpentine flow channel, landing to channel width ratio, PEMFC.

\section{INTRODUCTION}

The PEMFC engines can potentially interchange the internal combustion (IC) engine for transportation because it is clean, quiet, energy efficient, modular and capable of quick start-up [1]. The PEMFCs are considered to be appropriate solution to environmental and energy problems and are expected to soon become the most promising energy converters for automotive, stationary and portable applications, because of their high-energy density at low operating temperatures, quick start-up and zero emissions [2].The performance of the PEMFC depends on the various design and operating parameters revealed from the various literature survey. The performance of PEMFC with the active area of $5 \mathrm{~cm}^{2}$ under various operating conditions (pressures, temperatures and humidity of reactant gases) was investigated experimentally by Amirinejad et al. [3].The results revealed that the performance of PEMFC increased with the increase of the cell temperature and operating pressure. The performance of the cell, not only depends on the reactants humidification, but the anode humidification has also a considerable effect on the fuel cell performance.

The various operating parameters like cell operating pressure, temperature, and reactants on anode and cathode flow rate has been investigated experimentally for triangular channel geometry on $25 \mathrm{~cm}^{2}$ active area of PEMFC by Khazaee et al. [4].The results showed that the PEMFC performance can be enhanced by increase in the inlet temperature of reactants, cell temperature and inlet pressure. Santarelli \& Torchio [5] discussed the characterization of the behavior of a PEMFC effective area of $25 \mathrm{~cm}^{2}$ with various operating parameters (cell temperature, the anode and the cathode flow temperature in saturation and dry conditions, and reactant pressure). The results exhibited that the increase of temperature, reactants pressure and humidification at high cell temperature improved the performance of PEMFC. Also the performance has been improved with increased pressure along with humidification at both anode and cathode but, the increase of the operating pressure of dry reactants did not show any performance improvement.

Freire et al. [6] investigated the effect of operational parameters on the performance of PEMFC by using a serpentine flow field with rectangular and trapezoidal cross-section shape. The result concluded that the reactant humidification temperature has a significant impact on the effect of serpentine flow channels with trapezoidal cross-section on cell performance. Whereas, the effect of reactant humidification temperature of gases on the performance of the PEMFC was negligible when rectangular cross-section of serpentine flow channels was used. Hashemi et al. [7] investigated the performance of PEMFC with serpentine and straight flow fields. The results revealed that the serpentine flow field showed a better distribution of temperature and current density. The numerical results deviated from experimental results at high current densities because of assumption of the single-phase model which neglects the cathode side water flooding and anode side drying. The effect of gas flow fields on fuel cell performance with various flow channel designs like single and multiple channel serpentine, multiple channels parallel, pin type, interdigitated and spiral type flow channel with $23.5 \mathrm{~cm}^{2}$ effective area of the PEMFC has been investigated experimentally by Liu et al. [8]. The results showed that the single serpentine flow channel design gave the best performance amongst all the flow channel designs that exist. 
A three dimensional computational fluid dynamics (CFD) model was used to investigate the effects of serpentine flow channel curvature and length, pressure drop, velocity distribution on the performance of PEMFC by Jaruwasupant \& Khunatorn [9].The result revealed that the sharp curve was the best configuration because it has non-uniform flow distribution with low velocity and high pressure drop during the reactant flow. Ahmed \& Sung [10] investigated the performance of PEMFCs with different flow fields like a rectangular, trapezoidal and parallelogram using CFD. The results showed that a rectangular flow field gave higher cell voltages compared with parallelogram and trapezoidal flow fields. However, the trapezoidal flow field helped reactant diffusion, uniform reactant flow and current density circulations over the reacting area, results in lower cathode over potential of the fuel cell. Iranzo et al. [11] analyzed a CFD model of $50 \mathrm{~cm}^{2}$ active area with parallel and serpentine flow fields using the Ansys fluent software for performance enhancement of PEMFC. The result concluded that the serpentine flow field performed better than the parallel flow field performance also the results of a computational fluid dynamics fuel cell model cannot be trusted without any experimental validation was provided. In the serpentine flow field, it was observed that reactant humidification enhances the performance as it prevents the membrane electrode assembly from drying out. The most outstanding performance was obtained when the cell was operated with full humidification and pure oxygen, as concentration polarization was minimized and exchange current density enhanced. Imdat Taymaz and Elif Eker Kahveci [12] optimized the various operation parameters for the performance of PEM fuel cell using Response Surface Methodology. They concluded that the hydrogen flow rate, oxygen flow rate, humidification temperature and cell temperature were the main parameters to affect the performance of the PEM fuel cell. Kanani et al. [13] investigated the effects of operating conditions (cathode and anode stoichiometry, gas inlet temperature and cathode relative humidity) for serpentine flow channel on the performance of the PEM fuel cell by using Design of Experiments. Response surface methodology was used to model the relationship between cell potential and power with various operating input parameters. The results revealed that the low and high stoichiometry of reactant on anode and cathode cause the minimum cell power. Whereas the optimum ranges of stoichiometry of fuel and oxidants on anode and cathode leads to the best performance. The performance enhancement of the combined effect of design and operating parameters of serpentine and interdigitated flow channel with $25 \mathrm{~cm}^{2}$ active area of PEM fuel cell with four different parameters using optimization technique and CFD carried out by Lakshminarayanan and Karthikeyan [14]. The results revealed that the peak power density of interdigitated flow channel with landing to channel width (L:C)-1:2 showed better than the serpentine flow channel with L:C-1:2. The PEM fuel cell performance has been influenced by operating parameters (pressure, cell temperature, relative humidity and the stoichiometric ratio of reactants) and the design parameters (landing to channel width ratios, depth of the channel and number of passes on the flow channel)

The influence of six different cross-sections of the channel (square, triangle, parallelogram $14^{\circ}$, parallelogram $26^{\circ}$, trapezium and inverted trapezium) of $1.25 \mathrm{~cm}^{2}$ active area with single pass PEM fuel cell has been studied for various operating pressure and temperature. It is concluded that, square flow channel of single pass PEM fuel cell having a peak power density of $1.133 \mathrm{~W} / \mathrm{cm}^{2} @ 2.834 \mathrm{~A} / \mathrm{cm}^{2} \& 0.4 \mathrm{~V}$ for the given operating conditions. It is also concluded that, the variation of flow channel having less influence on the performance of single pass PEM fuel cell Lakshminarayanan et al [15]. Even though a large number of literature study revealed the effect of flow field design and operating parameters on the performance of PEMFC, this study differs from the fact that the PEMFC performance have been studied both numerically and experimentally with respect to various L: C-1:1, 1:2, 2:1and 2:2 configurations with operating parameters like operating pressure, temperature and stoichiometric ratio of reactant mass flow rate on serpentine flow channels of $25 \mathrm{~cm}^{2}$ active area of PEMFC. The RSM has been applied to optimize these operating and design parameters of PEMFC. The ANOVA (analysis of variance) analyses were used to compute the effects and contributions of the various parameters to the fuel cell maximum power density. The use of this design shows also how it is possible to reduce the number of experiments for time constraint

\section{NUMERICAL ANALYSIS}

The numerical analysis consisted of three phases: In the first phase, required three dimensional (3-D) PEM fuel cell with various L:C was modeled using Creo 2.0 tool. The modeling of the PEM fuel cell was done by creating seven parts, central membrane electrolyte (Nafion), catalyst layers, gas diffusion layers (GDL) and flow fields and assembling them to a single part in Creo 2.0 software. Figure 1(a) has shown the assembled view of PEM fuel cell model. The different configurations on serpentine flow field were modeled in Creo 2.0 tool for $25 \mathrm{~cm}^{2}$ active area of the PEM fuel cell as shown in the Figure 1 (b). The various geometrical models (land width to channel width of 1:1, 1:2 2:1 and 2:2) form the basis for creating a computational mesh. The assignments of zones for various parts have done by Workbench 14.0. The three dimensional geometry in Para solid format was imported to ICEM- 14.0 tool for finite volume discretization. Discretization is a process in which a single PEM fuel cell domain was divided into a number of small finite volumes referred as meshing. The necessary boundary conditions including the properties of flow fields, GDL, catalyst, membrane electrode on both cathode 
side and anode side were defined including the terminals with flow rate of hydrogen and oxygen. The temperature of the reactants and oxidants and the operating pressure was also defined.

In the second phase, the flow through the three dimensional PEM fuel cell was solved by solving the appropriate governing equations namely conservation of mass, conservation of momentum, conservation of energy, electrochemical equations, conservation of current and conservation of species. These governing equations were solved using CFD Fluent 14.0 software code for ensuring better convergence.

In the third phase, the numerical results predicted by the CFD code were post-processed for getting the current density, power density, hydrogen, oxygen and water concentration in the PEM fuel cell for analyzing the performance. The numerical investigation on PEM fuel cell performance in an active area of $25 \mathrm{~cm}^{2}$ with various lands to channel width ratios (L:C-1:1, 1:2, 2:1 and 2:2) on serpentine flow field has been investigated with various operating pressure and operating temperature by using CFD software and the corresponding values were validated experimentally.

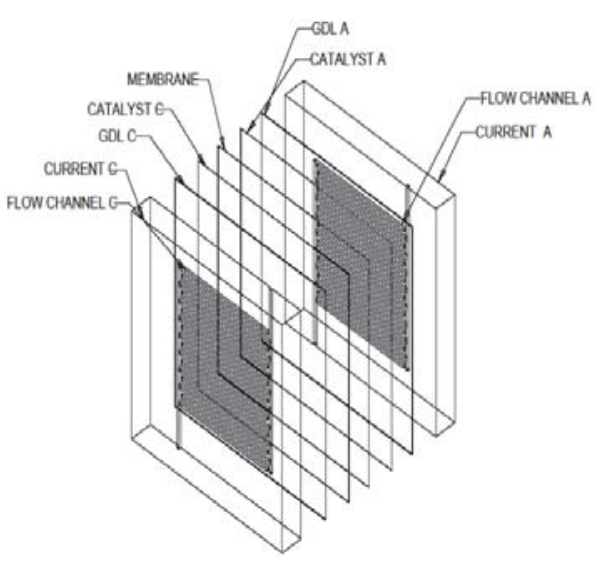

(a)

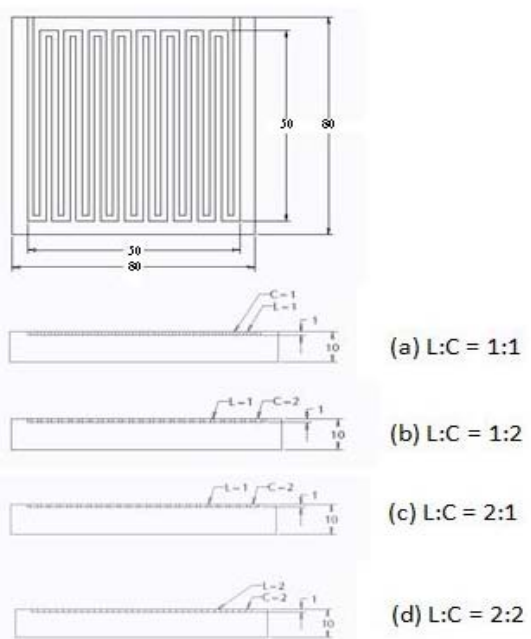

(b)

Fig. 1.(a) Assembled view of PEMFC and flow fields of (b) Serpentine flow field with various L:C of 1:1, 1:2, 2:1 and 2:2

\section{1) Discretization}

Grid generation for the PEM fuel cell model was done by ICEM- 14.0, commercially available CFD tool for meshing. As the available geometry has thickness varying from some microns to millimetres, it is quite complex to generate mesh as a single whole domain and so each part in the PEM fuel cell model was meshed individually by blocking method to have a specific control on the mesh size, suitable for producing pure hexahedral elements in order to capture the hydraulic and thermal boundary layers along with electro-chemical reactions. Except the current collectors, all the parts in the PEM fuel cell are defined as fluid zone, while the current collectors in the anode and cathode side are defined as solid in the cell zone condition. A fluid-fluid interface was given between membrane electrolyte, catalyst layer, Gas diffusion layer (GDL) and flow field on either side of the cell whereas a solid-fluid interface condition was assigned between current collectors and flow channel on both side of the PEM fuel cell. The grid independent study has been conducted for various L:C $\left(1: 1,1: 2,2: 1\right.$ and 2:2) of $25 \mathrm{~cm}^{2}$ active area of serpentine flow fields. Mass flow rate of Hydrogen $\left(\mathrm{m}_{\mathrm{H} 2}\right)$ is considered to be $4.2753 \times 10-7 \mathrm{~kg} / \mathrm{sec}$ in the anode side and mass flow rate of Oxygen $\left(\mathrm{m}_{\mathrm{O} 2}\right)$ is in the cathode side3.4202×10-6 kg/sec.

The boundary condition for anode and cathode inlet was set to mass flow inlet. The anode and cathode outlet was set to pressure outlet and the values given as 2 bar. Anode and cathode wall terminals were assigned as wall with no slip condition. Also the specification of the PEM fuel cell has been assigned as anode and cathode reference current density was set to 10000 and $20\left(\mathrm{~A} / \mathrm{cm}^{2}\right)$ respectively. Anode and cathode reference concentration was set to $1\left(\mathrm{kmol} / \mathrm{m}^{3}\right)$, Anode and cathode exchange co efficient was set to 2 . Reference Diffusivity of $\mathrm{H}_{2}, \mathrm{O}_{2}$ and $\mathrm{H}_{2} \mathrm{O}$ was set to $3 \mathrm{e}-5\left(\mathrm{~m}^{2} / \mathrm{s}\right)$

\section{2) Mathematical model}

The PEM fuel cell model was solved for general governing equations using CFD Fluent 14.0 software code. The Fuel cells and electrolysis model was turned on to connect the fluid dynamics equation and electrochemical model. The following assumptions were made to reduce the complexity in the simulation. The reactant gases and oxidizer were considered as ideal gas, the flow was steady, laminar and incompressible and Temperature was constant throughout the process. The isotropic porous zones considered to catalyst layers, gas diffusion 
layers, and the membrane electrolyte. Diffusion mechanism and electro-osmotic drag aids the transfer of liquid water through the membrane electrolyte and the effect of gravity was neglected.

The corresponding model has been simulated by simultaneous equations like conservation of mass, momentum, energy, species concentration, Butler-Volmer equation, Joule heating reaction and the Nernst equation to obtain reaction kinetics of the PEM fuel cell namely mass fraction of $\mathrm{H}_{2}, \mathrm{O}_{2}, \mathrm{H}_{2} \mathrm{O}$, static pressure, temperature and current flux density distribution in flow field using CFD Fluent 14.0 software packages to get the maximum power density corresponding to the cell potential. A control volume approach based on commercial solver FLUENT 14.0 has been used to solve the various governing equations.3-Dimensional, steady state, laminar, double precision serial processing mode was used in this simulation. The species concentration on anode side of $\mathrm{H}_{2}, \mathrm{O}_{2}$, and $\mathrm{H}_{2} \mathrm{O}$ has $0.8,0$, and 0.2 respectively. Similarly, on the cathode side has $0,0.2$ and 0.1 respectively. The porosity and viscous resistance at anode and cathode side has 0.5 and $1 \mathrm{e} 12\left(1 / \mathrm{m}^{2}\right)$. Open circuit voltage (OCV) has set at $0.95 \mathrm{~V}$ in the cathode and anode has grounded. The cathode voltage has been varied from $0.05 \mathrm{~V}$ to $0.95 \mathrm{~V}$ used for solving kinetics reaction in order to get the current flux density, $\mathrm{H}_{2}, \mathrm{O}_{2}$, and $\mathrm{H}_{2} \mathrm{O}$ fractions along with the flow field. Multigrid settings modified as F-Cycle for all equations and entered termination restriction value has set as 0.001 for $\mathrm{H}_{2}, \mathrm{O}_{2}, \mathrm{H}_{2} \mathrm{O}$ and water saturation. The proton and electric potential values have been set at 0.0001 . The stabilized version of the (biconjugate gradient method) Krylovspace method of BCGSTAB has selected for $\mathrm{H}_{2}, \mathrm{O}_{2}, \mathrm{H}_{2} \mathrm{O}$, water saturation, electric and proton potential.

\section{3) Design of experiments}

The optimization various combinations of operating parameters like operating pressure, temperature and stoichiometric ratio of inlet gases on the response with various landing to channel width ratio of 1:1, 1:2, 2:1 and 2:2 obtained using the Response Surface Methodology by Minitab 17 software. In this study the central composite design (CCD) was used to investigate the effect of various operating parameters and design parameters. The combinations of various operating and design parameters were given input to the CFD Fluent software to get the corresponding power density. Operating pressure (1, 1.5 and 2 bar), temperature (323, 333 and $343 \mathrm{~K})$ and stoichiometric ratio of fuel and oxidant (3, 3.5 and 4 times to the theoretical value) were selected as independent variables. In addition, the power density obtained from CFD fluent software for four type of $\mathrm{L}: \mathrm{C}$ was used as response to determine the combined effects of these variables. The total number of run with three variables on one design of L:C was 15 . Hence the serpentine flow channel with various L:C 1:1, 1:2, 2:1 and 2:2, the total run with CFD fluent software was 60 . The numerical values of the response variables for central composite design with various landing to channel width ratio of 1:1, 1:2, 2:1 and 2:2 on serpentine flow channel has been assigned by using Minitab 17.

\section{4) Experimental setup}

A computer (V.5.22 software package) interfaced fuel cell test equipment Bio-Logic FCT-50S has been used for experimental analysis as shown in the Fig.3. For the experimental analysis, a commercially available gas diffusion electrode (GDE) sheet (Paxi-Tech from France) has been used. This GDE has carbon paper as its GDL or Diffusion medium and $40 \% \mathrm{Pt} / \mathrm{C}$ as catalyst with a loading of $0.5 \mathrm{mg} / \mathrm{cm}^{2}$. The required size of (Nafion 115) membrane has been sandwiched with GDE on both sides by hot pressing with the pressure of $50 \mathrm{~kg} / \mathrm{cm}^{2}$ and the temperature of $130^{\circ} \mathrm{C}$ for $3 \mathrm{~min}$ in the preparation of membrane electrode assembly (MEA). Highly purified hydrogen (99.99\%) and pure oxygen has been used as fuel and oxidant respectively. The gold coated copper plates have been used for a current collector in the anode and cathode side. The MEA has been humidified properly and confirmed that it works at its peak power value. In order to humidify the MEA, an activation procedure is done by the application of current pulse and the voltage pulse programs. The potential can be set to an absolute value or can be set relative to the initial voltage at the beginning of the technique.

For the reliability of the numerical results, experimental validation of $25 \mathrm{~cm}^{2}$ PEM fuel cell with various land to channel width ratio of serpentine flow fields have been done. Hence the present studies also consideration of operating pressure as 2 bar, cell temperature as $343 \mathrm{~K}$ and the inlet mass flow rate of the reactants is four times the theoretical mass flow rate. 


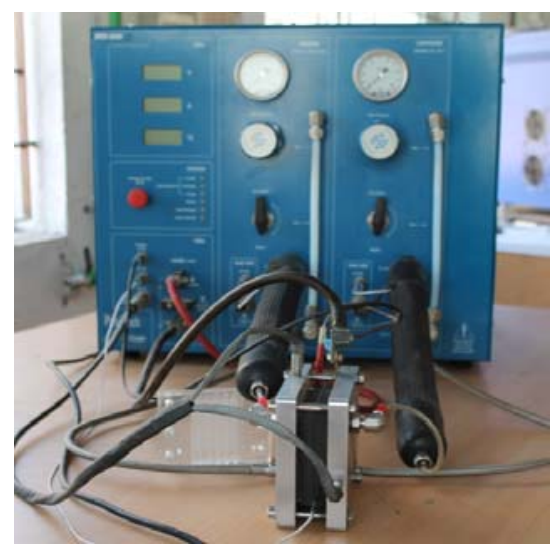

Fig. 3. Bio-Logic Test station FCT 50S with $25 \mathrm{~cm}^{2}$ active area of single cell PEMFC

\section{III.RESULTS AND DISCUSSIONS}

The various peak power density and current density for combination of design and operating parameters as per CCD with serpentine flow fields has shown in the Table 1.The landing to channel width ratio of 1:1 for serpentine flow field has shown maximum current and power densities of $0.628 \mathrm{~A} / \mathrm{cm}^{2}$ and $0.298 \mathrm{~W} / \mathrm{cm}^{2}$ respectively and minimum current and power densities of $0.302 \mathrm{~A} / \mathrm{cm}^{2}$ of and $0.136 \mathrm{~W} / \mathrm{cm}^{2}$ respectively. Similarly for L:C of 1:2 and 2:1 having maximum current density of $0.638 \mathrm{~A} / \mathrm{cm}^{2}$ and $0.637 \mathrm{~A} / \mathrm{cm}^{2}$ respectively, and the power density of $0.303 \mathrm{~W} / \mathrm{cm}^{2}$ and $0.287 \mathrm{~W} / \mathrm{cm}^{2}$ respectively. The minimum current and power densities for the same L:C ratios have $0.352 \mathrm{~A} / \mathrm{cm}^{2}$ and $0.399 \mathrm{~A} / \mathrm{cm}^{2} \& 0.150 \mathrm{~W} / \mathrm{cm}^{2}$ and $0.180 \mathrm{~W} / \mathrm{cm}^{2}$ respectively. For the landing to channel width ratio of 2:2 has shown maximum current density of $0.612 \mathrm{~A} / \mathrm{cm}^{2}$ and power density of $0.291 \mathrm{~W} / \mathrm{cm}^{2}$ and minimum current density of $0.409 \mathrm{~A} / \mathrm{cm}^{2}$ and power density of 0.184 $\mathrm{W} / \mathrm{cm}^{2}$. Hence the operating pressure of $2 \mathrm{bar}$, cell temperature of $343 \mathrm{~K}$ and 3 stoichiometric ratio of gases yield the maximum performance compared with various pressure and cell temperature.

TABLE 1. Peak power density with various L:C of serpentine flow fields on $25 \mathrm{~cm}^{2}$ PEM fuel cell

\begin{tabular}{|c|c|c|c|c|c|c|c|c|c|c|}
\hline \multicolumn{3}{|c|}{$\begin{array}{l}\text { Operating } \\
\text { condition }\end{array}$} & \multicolumn{2}{|c|}{ L:C-1:1 } & \multicolumn{2}{|c|}{ L:C-1:2 } & \multicolumn{2}{|c|}{ L:C-2:1 } & \multicolumn{2}{|c|}{ L:C-2:2 } \\
\hline 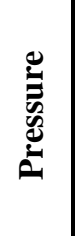 & 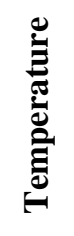 & 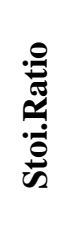 & 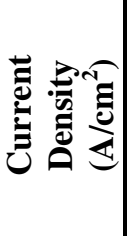 & 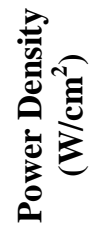 & 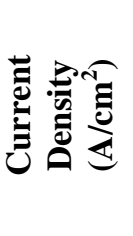 & 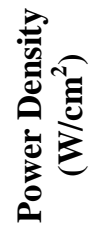 & 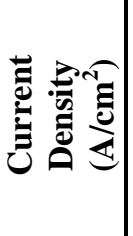 & 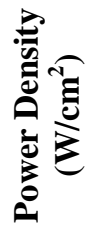 & 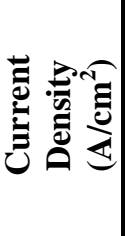 & 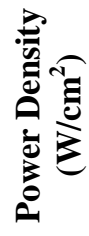 \\
\hline 1 & 323 & 4 & 0.402 & 0.181 & 0.421 & 0.189 & 0.435 & 0.196 & 0.409 & 0.184 \\
\hline 1 & 343 & 3 & 0.302 & 0.136 & 0.352 & 0.150 & 0.408 & 0.194 & 0.412 & 0.196 \\
\hline 1 & 343 & 4 & 0.310 & 0.140 & 0.395 & 0.168 & 0.399 & 0.180 & 0.411 & 0.185 \\
\hline 2 & 343 & 3 & 0.628 & 0.298 & 0.638 & 0.303 & 0.637 & 0.287 & 0.612 & 0.291 \\
\hline 2 & 323 & 3 & 0.521 & 0.247 & 0.632 & 0.269 & 0.603 & 0.256 & 0.524 & 0.236 \\
\hline 2 & 333 & 3.5 & 0.602 & 0.271 & 0.654 & 0.294 & 0.628 & 0.283 & 0.531 & 0.252 \\
\hline 1.5 & 333 & 3 & 0.550 & 0.248 & 0.601 & 0.270 & 0.645 & 0.258 & 0.608 & 0.274 \\
\hline 1 & 323 & 3 & 0.510 & 0.230 & 0.611 & 0.260 & 0.516 & 0.232 & 0.562 & 0.239 \\
\hline 1.5 & 343 & 3.5 & 0.621 & 0.264 & 0.624 & 0.265 & 0.584 & 0.263 & 0.587 & 0.249 \\
\hline 1.5 & 333 & 3.5 & 0.601 & 0.270 & 0.615 & 0.277 & 0.538 & 0.256 & 0.513 & 0.244 \\
\hline 2 & 343 & 4 & 0.632 & 0.284 & 0.645 & 0.290 & 0.685 & 0.274 & 0.598 & 0.269 \\
\hline 1.5 & 323 & 3.5 & 0.527 & 0.237 & 0.416 & 0.187 & 0.517 & 0.233 & 0.496 & 0.223 \\
\hline 2 & 323 & 4 & 0.528 & 0.238 & 0.444 & 0.211 & 0.612 & 0.275 & 0.556 & 0.250 \\
\hline 1 & 333 & 3.5 & 0.519 & 0.208 & 0.509 & 0.216 & 0.508 & 0.203 & 0.498 & 0.212 \\
\hline 1.5 & 333 & 4 & 0.615 & 0.261 & 0.602 & 0.286 & 0.575 & 0.259 & 0.518 & 0.233 \\
\hline
\end{tabular}


The Fig.2 shows the power density as a function of pressure temperature and stoichiometric ratio of L:C 1:2. The Fig.2(a) exhibited power density as a function of stoichiometric ratio of reactants and temperature and is clearly evident that the stoichiometric ratio and the temperature increases the power density also increases at certain level then gradually decreases even though the stoichiometric ratio increases. The Fig.2(b) showed the power density as a function of pressure and temperature. It showed that the pressure and temperature increases the power density also increases .The Fig.2(c) showed the power density as a function of pressure and stoichiometric ratio of the reactants. The power density increases at certain level then gradually decreases even though the stoichiometric ratio increases.

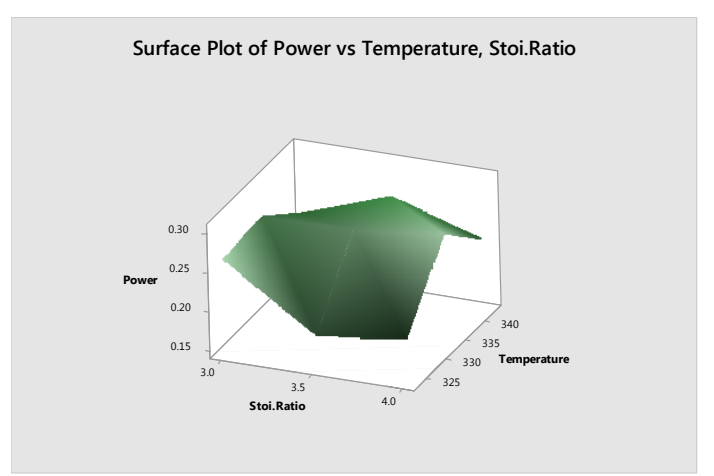

(a)

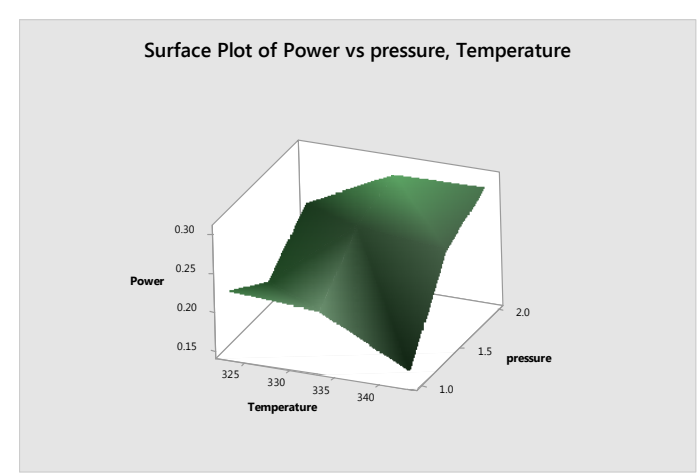

(b)

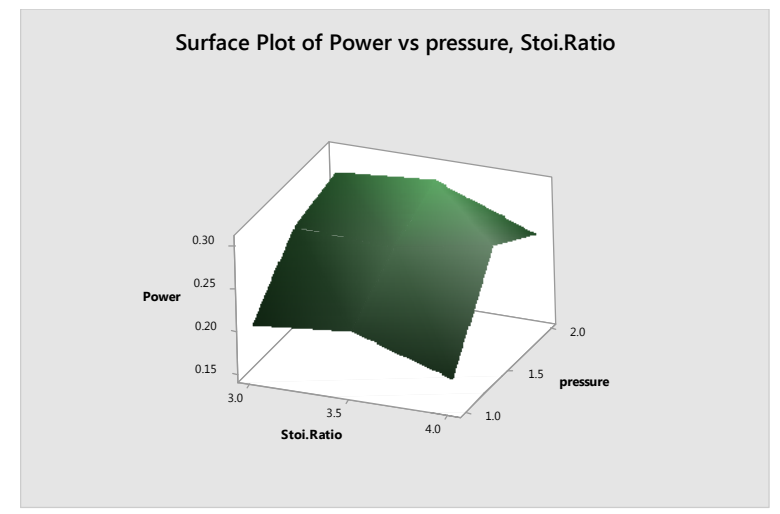

(c)

Fig. 2. Comparison of power with various operating parameters of $25 \mathrm{~cm}^{2}$ active area of Serpentine flow field

An experimental investigation of L:C of 1:2 \& 2:1 for serpentine flow fields for $25 \mathrm{~cm}^{2}$ PEM fuel cell performance were carried out in the above mentioned experimental setup and for L:C of 1:1 \& 2:2 for serpentine flow fields has been considered by previously published paper by Karthikeyan et al. [16]. Also the values have been confirmed by conducting experiment once again with the same parameters. The experimental performance of various landing to channel width ratio of serpentine flow field have been shown in the Fig.3. 


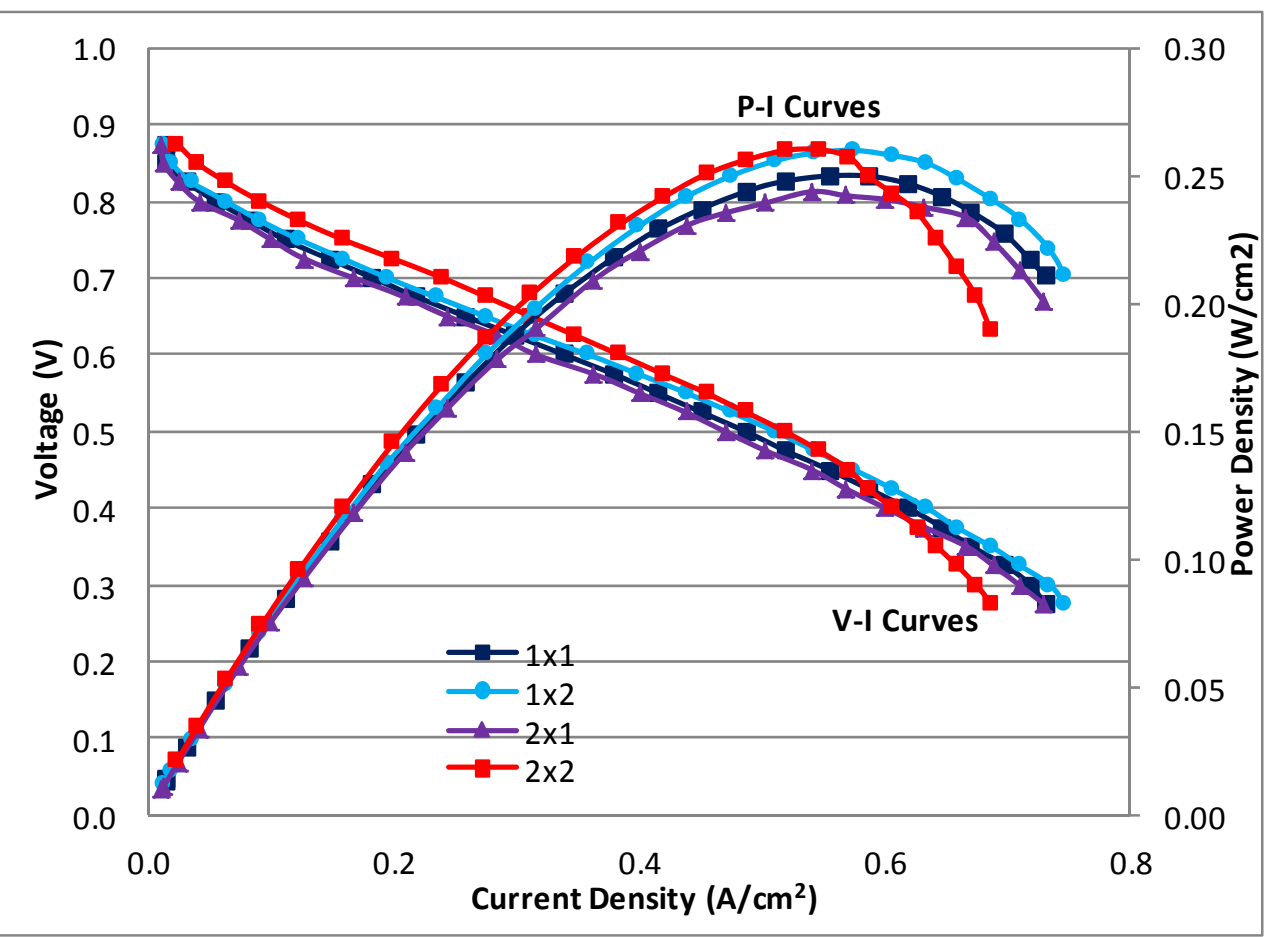

Fig. 3. Experimental performance of $25 \mathrm{~cm}^{2}$ active area of PEM fuel cell with various lands to channel width ratios of Serpentine flow fields

Based on the experimental studies, the peak power density of the serpentine flow field of various L:C $(1: 1,1: 2,2: 1$ and $2: 2)$ have been $0.250 \mathrm{~W} / \mathrm{cm}^{2}, 0.260 \mathrm{~W} / \mathrm{cm}^{2}, 0.247 \mathrm{~W} / \mathrm{cm}^{2}$ and $0.260 \mathrm{~W} / \mathrm{cm}^{2}$ respectively. The corresponding current densities were $0.556 \mathrm{~A} / \mathrm{cm}^{2}, 0.576 \mathrm{~A} / \mathrm{cm}^{2}, 0.549 \mathrm{~A} / \mathrm{cm}^{2}$ and $0.548 \mathrm{~A} / \mathrm{cm}^{2}$ respectively. It was also observed in the experimental studies, the maximum peak power performance of the serpentine flow field has been $0.260 \mathrm{~W} / \mathrm{cm}^{2}$ for L:C-1:2 \& 2:2 and a minimum of $0.254 \mathrm{~W} / \mathrm{cm}^{2}$ for L:C-2:1 with $5.26 \%$ deviation on power performance. It was found that the numerical studies on serpentine flow field results has been deviated from the experimental results for various L:C of 1:1, 1:2, 2:1 and 2:2 as $19.2 \%, 16.5 \%, 16.2 \%$ and $11.9 \%$ respectively as shown in Table 2 .

TABLE 2. Validation with experimental results of serpentine flow channel of PEM fuel cell

\begin{tabular}{|c|c|c|c|c|c|}
\hline Type & Values & L:C & $\begin{array}{l}\text { Current density } \\
\left(\mathrm{A} / \mathrm{cm}^{2}\right)\end{array}$ & $\begin{array}{c}\text { Peak power } \\
\text { density }\left(\mathrm{W} / \mathrm{cm}^{2}\right)\end{array}$ & $\begin{array}{c}\text { \% Deviation of } \\
\text { Peak Power density }\end{array}$ \\
\hline \multirow{8}{*}{ 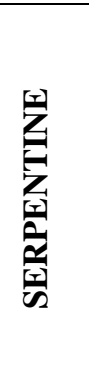 } & Numerical & \multirow{2}{*}{$1: 1$} & 0.628 & 0.298 & \multirow{2}{*}{19.2} \\
\hline & Experimental & & 0.556 & 0.250 & \\
\hline & Numerical & \multirow{2}{*}{$1: 2$} & 0.638 & 0.303 & \multirow{2}{*}{16.5} \\
\hline & Experimental & & 0.576 & 0.260 & \\
\hline & Numerical & \multirow{2}{*}{$2: 1$} & 0.637 & 0.287 & \multirow{2}{*}{16.2} \\
\hline & Experimental & & 0.549 & 0.247 & \\
\hline & Numerical & \multirow{2}{*}{$2: 2$} & 0.612 & 0.291 & \multirow{2}{*}{11.9} \\
\hline & Experimental & & 0.548 & 0.260 & \\
\hline
\end{tabular}

\section{IV.CONCLUSION}

The RSM has been used to find out the optimum power density of $25 \mathrm{~cm}^{2}$ active area of the PEMFC by optimizing the various operating parameters with various landing to channel width of serpentine flow channel. The numerical results have been compared with the experimental validation with $25 \mathrm{~cm}^{2}$ active area of the PEM fuel cell. The serpentine flow field with L:C of 1:2 \& 2:2 have produced the numerical peak power density of 0.303 and $0.291 \mathrm{~W} / \mathrm{cm}^{2}$ respectively and experimental peak power density \& $0.260 \mathrm{~W} / \mathrm{cm}^{2}$ with deviation of 16.5 and $11.9 \%$ respectively. A reasonable confirmation can be made with numerical studies on PEMFC performance with various landing to channel width configurations of serpentine flow fields. 


\section{REFERENCES}

[1] Sukkee Um, C.-Y. Wang,z and K. S. Chen., "Computational Fluid Dynamics Modeling of Proton Exchange Membrane Fuel Cells,” Journal of The Electrochemical Society, 147 (12) , pp 4485-4493, 2000.

[2] Mengbo Ji and Zidong Wei, “A Review of Water Management in Polymer Electrolyte Membrane Fuel Cells,” Energies, 2, pp 10571106, 2009.

[3] Amirinejad, M, Rowshanzamir, S \& Eikani, MH, "Effects of operating parameters on performance of a proton exchange membrane fuel cell,” Journal of Power Sources, vol. 161, no. 2, pp. 872-875, 2006.

[4] Khazaee, I, Ghazikhani, M \& Mohammadiun, M, 'Experimental and thermodynamic investigation of a triangular channel geometry PEM fuel cell at different operating conditions', Scientia Iranica, vol. 19, no. 3, pp. 585-593, 2012.

[5] Santarelli, M \& Torchio, M, "Experimental analysis of the effects of the operating variables on the performance of a single PEMFC', Energy Conversion and Management, vol. 48, no. 1, pp. 40-51, 2007.

[6] Freire, LS, Antolini, E, Linardi, M, Santiago, EI \& Passos, RR, "Influence of operational parameters on the performance of PEMFCs with serpentine flow field channels having different (rectangular and trapezoidal) cross-section shape', International Journal of Hydrogen Energy, vol. 39, no. 23, pp. 12052-12060, 2014.

[7] Hashemi, F, Rowshanzamir, S \& Rezakazemi, M, "CFD simulation of PEM fuel cell performance: effect of straight and serpentine flow fields,” Mathematical and Computer Modelling, vol. 55, no. 3, pp. 1540-1557, 2014.

[8] Liu, H, Li, P, Juarez-Robles, D, Wang, K \& Hernandez-Guerrero, A, "Experimental study and comparison of various designs of gas flow fields to PEM fuel cells and cell stack performance," Frontiers in Energy Research, vol. 2, no. 2. 2014.

[9] Jaruwasupant, N \& Khunatorn, Y, "Effects of difference flow channel designs on Proton Exchange Membrane Fuel Cell using 3-D Model,” Energy procedia, vol. 9, pp. 326-337, 2011.

[10] Ahmed, D.H \& Sung, HJ, "Effects of channel geometrical configuration and shoulder width on PEMFC performance at high current density,” Journal of Power Sources, vol. 162, no. 1, pp. 327-339, 2006.

[11] Iranzo, A, Muñoz, M, Rosa, F \& Pino, J, "Numerical model for the performance prediction of a PEM fuel cell. Model results and experimental validation,” International Journal of Hydrogen Energy, vol. 35, no. 20, pp. 11533-11550, 2010.

[12] Imdat Taymaz and Elif Eker Kahveci, "Experimental investigation on water and heat management in a PEM fuel cell using response surface methodology,” International journal of hydrogen energy. 1 -9, 2014.

[13] Kanani, H, Shams, M, Hasheminasab, M \& Bozorgnezhad, A, "Model development and optimization of operating conditions to maximize PEM FUEL CELL performance by response surface methodology,” Energy Conversion and Management. 93, 9-22, 2015.

[14] Lakshminarayanan, V \& Karthikeyan, P, "Optimization of Flow Channel Design and Operating Parameters on Proton Exchange Membrane Fuel Cell Using Mat lab,” Periodica Polytechnica Chemical Engineering. Budapest Univ Technology Economics. 60, 3, 173-180, 2016.

[15] V.Lakshminarayanan, P.Karthikeyan, M.Muthukumar,A.P.Senthilkumar, B.Kavin, A. Kavyaraj, "Numerical investigation of performance studies on single pass PEM fuel cell with various flow channel design,” Applied Mechanics and Materials, Vols. 592-594 pp 1672-1676, 2014.

[16] Karthikeyan, P, Velmurugan, P, George, AJ, Kumar, RR \& Vasanth, R, "Experimental investigation on scaling and stacking up of proton exchange membrane fuel cells,” International Journal of Hydrogen Energy, 39, 21, 11186-11195, 2014. 